\title{
Spinal Paraganglioma Adherent to the Cauda Equina
}

\author{
Han San Oh, Tae Wan Kim, Kwan Ho Park \\ Department of Neurosurgery, VHS Medical Center, Seoul, Korea
}

Paragangliomas are rare among intradural spinal tumors. Most of them are benign, but aggressive behavior and local recurrence can occur. Cases of paraganglioma are, difficult to diagnose radiologically; hence, diagnosis is confirmed histopathologically. Radiologically, paragangliomas are similar to ependymomas, and, histopathologically, they are similar to neuroendocrine tumors. We evaluated the case of a 76-year-old woman with a spinal paraganglioma that was associated with back pain and radiating pain in both the lower extremities. She underwent an operation, and her symptoms were relieved. Here, we describe a rare case of paraganglioma that was adherent to the cauda equina.

Key Words: Paraganglioma $\cdot$ Cauda equina $\cdot$ Operation

\section{INTRODUCTION}

Paragangliomas are rare among intradural spinal tumors. Most of them occur on the periphery of the cauda equina. Radiologically, they are similar to ependymomas, and histopathologically, they are similar to neuroendocrine tumors. Most of them are non-secreting tumors, although they are of sympathetic origin. Back pain is the most common symptom, and they are not associated with tachycardia, flushing, or hypertension. The treatment of choice is total surgical resection, and no additional treatment is needed with total resection. Most of them are benign, but, recurrence can occur in cases involving a failure of the total resection. Radiotherapy may be needed in cases of incomplete removal and recurrence. We describe a rare case of a paraganglioma that was adherent to the cauda equina that presented with low back pain and radiating pain in both the lower extremities.

\section{CASE REPORT}

A 76-year-old female visited our department with com-

- Received: October 8, 2014 • Revised: November 8, 2014

- Accepted: November 10, 2014

Corresponding Author: Tae Wan Kim, MD

Department of Neurosurgery, VHS medical center, 53 Jinhwangdo-ro, 61-gil, Gangdong-gu, Seoul 134-791, Korea

Tel: +82-2-2225-1363, Fax: + 82-2-2225-4152

E-mail: euro3399@naver.com

@This is an Open Access article distributed under the terms of the Creative Commons Attribution Non-Commercial License (http://creativecommons.org/ licenses/by-nc/3.0/) which permits unrestricted non-commercial use, distribution, and reproduction in any medium, provided the original work is properly cited. plaints of low back pain and radiating pain in both the lower extremities for more than two months. She had no specific disease history, except for hypertension. The neurologic examination revealed no motor or sensory changes or pathologic reflexes. Magnetic resonance (MR) imaging revealed a lobulated sausage-like intradural mass (Fig. 1). She underwent a total laminectomy and near-total tumor removal. During the operation, the dura was firm, tense, and slightly bulging (Fig. 2A). After opening the dura, a reddish, friable, and well-marginated mass was observed (Fig. 2B). We removed the mass near-totally except for the lesion that was adherent to the cauda equina. The lower back pain and radiating pain in both the lower extremities were diminished. A histopathological examination confirmed that it was a paraganglioma (Fig. 3). Radiation therapy was recommended due to the incomplete resection, but the patient refused. Thus, we did not provide any additional treatment involving chemotherapy and radiotherapy. She was discharged with no neurologic deficits.

\section{DISCUSSION}

Paragangliomas are uncommon, benign, and well-circumscribed vascular tumors. Spinal paragangliomas commonly occur around the cauda equina. Back pain and radiating pain to the lower extremities are common symptoms. Extradural paragangliomas may compress the spinal cord, resulting in paraparesis ${ }^{5}$.

From a pathologic point of view, paragangliomas are similar to parasympathetic tumors. However, functional paragangliomas are rare ${ }^{6}$. Histopathologically they are similar to parasympathetic tumors that occur in the carotid body or glomus 
region. Althogh they are also similar to catecholamine-secreting tumors, symptoms of flushing, tachycardia, or hypertension are rare. However, a case in which hypertension was controlled after thoracic paraganglioma removal has been reported ${ }^{12)}$.

Preoperative diagnosis is difficult with radiological tools. MR images of paragangliomas in the cauda equina region are non-specific and are relatively isointense on T1-weighted images and hyperintense on T2-weighted images. Cystic components may be found within the tumor ${ }^{3)}$.

Differential diagnosis between paragangliomas and ependymomas is difficult. Routine staining is similar in paragang-
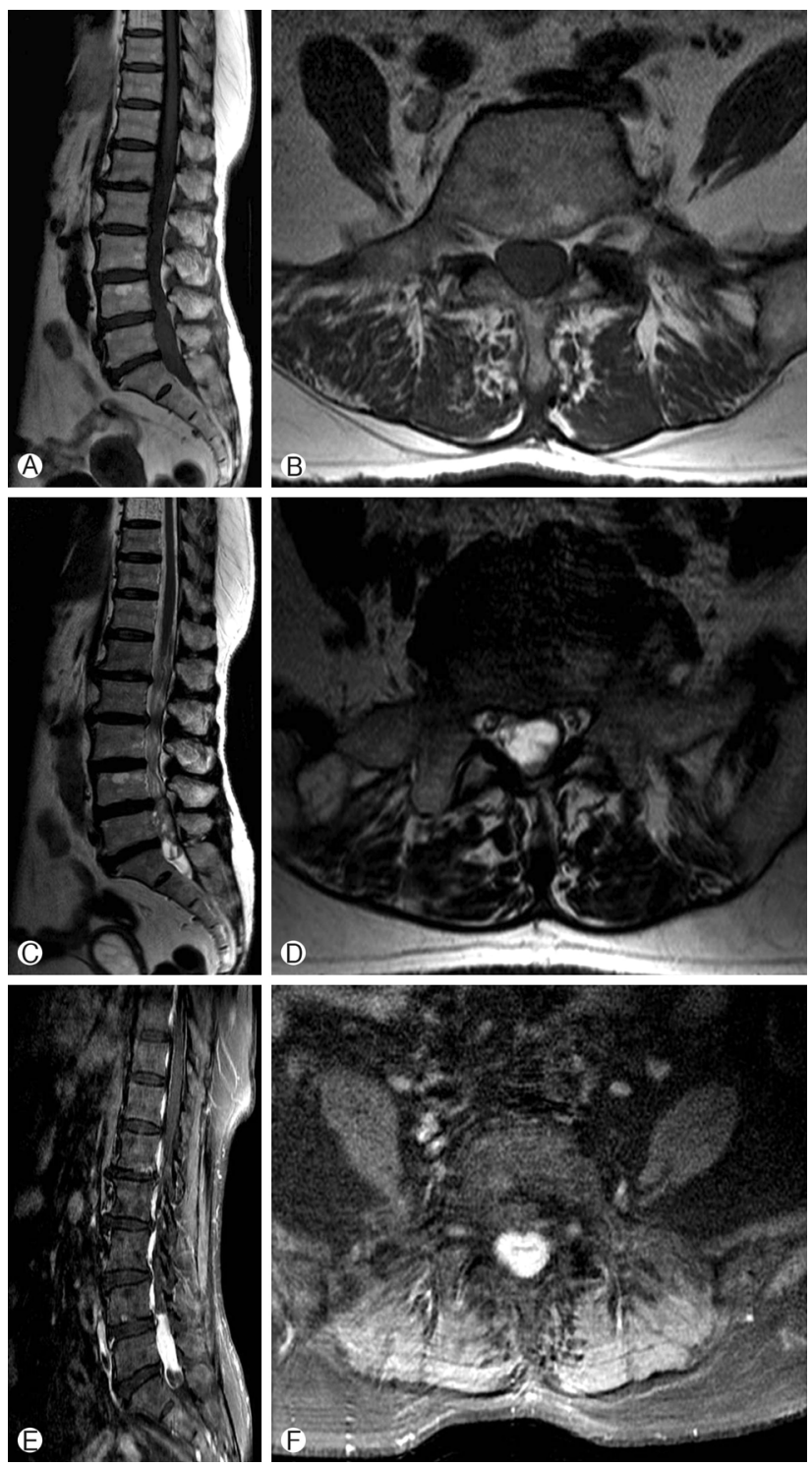

Fig. 1. Preoperative magnetic resonance (MR) imaging shows a low intensity mass on a $\mathrm{Tl}$ weighted image $(\mathrm{Wl} ; \mathrm{A}, \mathrm{B})$ and a high intensity mass on a T2 WI (C, D). After gadolinium enhancement, a well-enhanced mass is noted $(E, F)$. liomas and ependymomas ${ }^{2}$. Neuronal markers, such as synaptophysin, are helpful. Immunohistochemically, neuron-specific enolase, synaptophysin, and chromogranin staining are positive ${ }^{2)}$.

In the cauda equina region, it is very difficult to distinguish paragangliomas from ependymomas. Cauda equina paragangliomas are classified as grade I on the World Health Organization (WHO) classification. However, ependymomas are classified as WHO grade II-III. Thus, paraganglioma-ependymoma differentiation is very important ${ }^{8,9)}$.

Complete surgical resection is the treatment of choice. After total removal, the prognosis is relatively good. Locations in the cauda equina are exceptional ${ }^{1}$. Recurrence after surgery on a paraganglioma in the cauda equina region, especially if it is encapsulated, is rarely encountered ${ }^{2}$. The surgical goal is complete total resection with preservation of the surrounding
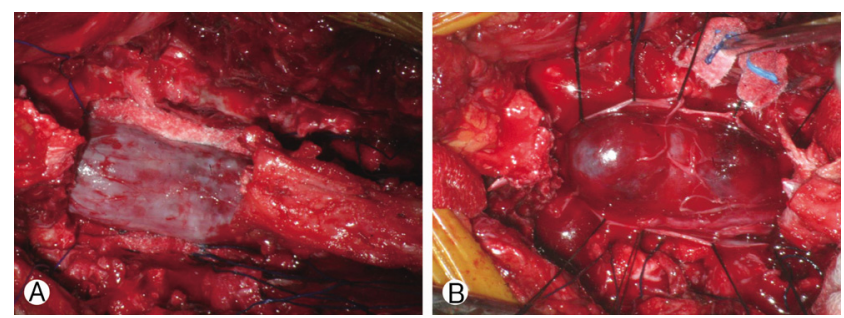

Fig. 2. An intraoperative photography shows a tense and bulged dura $(\mathrm{A})$ and a reddish, friable mass $(\mathrm{B})$.
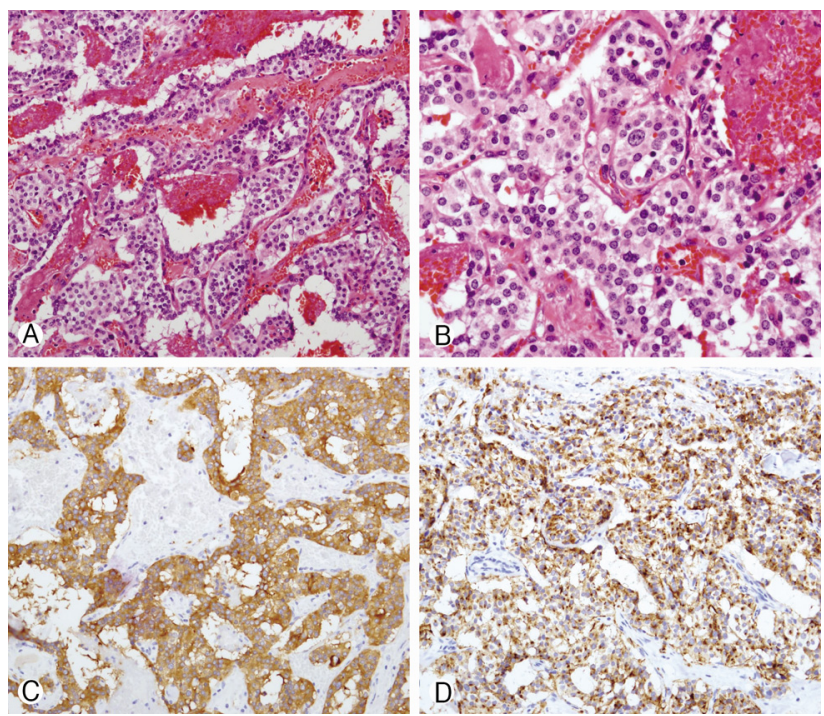

Fig. 3. (A) Histologically, the tumor cells are disposed in nests of lobules (Zellballen), which are surrounded by a delicate capillary network (Hematoxylin and Eosin stain, $\times 200$ ). (B) The tumor cells have central round to oval nuclei; and cytoplasm is usually eosinophilic and finely granular (Hematoxylin and Eosin stain, $\times 400$ ). Immunohistochemistry reveals that the tumor cells show immunoreactivity for synaptophysin (C) and chromogranin $A(D)$. 
nerve roots ${ }^{1)}$. Our case involved an encapsulated paraganglioma. Thus, we did not treat the patient any additional therapy, and conducted a close follow-up.

Radiation therapy is recommended in cases of incomplete removal or recurrence. However, the effects of radiation therapy are controversial ${ }^{9,10)}$. After incomplete surgical resection, prolonged postoperative observations are mandatory because of the slow evolution of paragangliomas ${ }^{4}$.

Distant metastases very rarely occur ${ }^{5}$, and metastatic paragangliomas of the spine have been reported ${ }^{7,11)}$.

\section{CONCLUSION}

We describe a case involving a spinal paraganglioma that was adherent to cauda equina. A histopathological examination confirmed the diagnosis. Total resection was difficult in this case due to adhesion to the cauda equina, and close follow-up may therefore be needed.

\section{REFERENCES}

1. Aghakhani N, George B, Parker F: Paraganglioma of the cauda equina region-report of two cases and review of the literature. Acta Neurochir (Wien) 141:81-87, 1999

2. Bak J, Olsson Y, Grimelius L, Spannare B: Paraganglioma of the cauda equina. APMIS 104:234-240, 1996

3. Faro SH, Turtz AR, Koenigsberg RA, Mohamed FB, Chen CY, Stein H: Paraganglioma of the cauda equina with associated intramedullary cyst: MR findings. AJNR Am J Neuroradiol 18: 1588-1590, 1997

4. Gelabert-Gonzalez M: Paragangliomas of the lumbar region. J Neurosurg Spine 2:354-365, 2005

5. Houten JK, Babu RP, Miller DC: Thoracic paraganglioma presenting with spinal cord compression and metastases. J Spinal Disord Tech 15:319-323, 2002

6. Jeffs GJ, Lee GY, Wong GT: Functioning paraganglioma of the thoracic spine: case report. Neurosurgery 53:992-994, 2003

7. Lau D, La Marca F, Camelo-Piragua S, Park P: Metastatic paraganglioma of the spine: case report and review of the literature. Clin Neurol Neurosurg 115:1571-1574, 2013

8. Midi A, Yener AN, Sav A, Cubuk R: Cauda equina paraganglioma with ependymoma-like histology: a case report. Turk Neurosurg 22:353-359, 2012

9. Mishra T, Goel NA, Goel AH: Primary paraganglioma of the spine: a clinicopathological study of eight cases. J Craniovertebr Junction Spine 5:20-24, 2014

10. Naim-ur-Rahman, Sadiq S, Jamjoom ZA: Paraganglioma of the cauda equina: case report and review of the literature. $\mathrm{Br} \mathrm{J}$ Neurosurg 5:409-415, 1991

11. Oh JI, Lim DJ, Park JY, Chung HS, Suh JK, Lee HK: A case of metastatic malignant paraganglioma causing spinal root compression. J Korean Neurosurg Soc 26:1158-1162, 1997

12. Zileli M, Kalayci M, Basdemir G: Paraganglioma of the thoracic spine. J Clin Neurosci 15:823-827, 2008 